\title{
Homework assignments to enhance student engagement in secondary education
}

\author{
Maartje Buijs • Wilfried Admiraal
}

Received: 1 November 2011 /Revised: 1 May 2012 / Accepted: 4 June 2012 /

Published online: 20 June 2012

C The Author(s) 2012. This article is published with open access at Springerlink.com

\begin{abstract}
Secondary school teachers often complain that their students show a disengaged attitude in class. Students do not prepare for lessons, they show a passive attitude towards classroom activities and they have a limited awareness of their own learning process. Based on a pilot study, four homework assignments were designed, implemented, and evaluated to stimulate students to prepare for history lessons and subsequently show a more engaged attitude and involvement in classroom activities. Two groups of, in total 50, 11th grade students of pre-university education participated in one group pre- post-test design. Data on student engagement in class is gathered by class observation: time on task, their level of activity, and amount and variety of questions students asked. Students' motivation and perceived learning outcomes are measured by means of a self-report: Three of the four homework assignments (jigsaw, preparing analytical skills, and the fragmented assessment) showed increase in student engagement compared to the baseline of the first two classes. Implications for practice are discussed.
\end{abstract}

Keywords Student engagement $\cdot$ Homework assignments $\cdot$ Activating instructions · Active students

Studies have characterized high school students, in particular, as bored, staring out classroom windows, counting the seconds for the bell to ring, and pervasively disengaged from the learning process (Goodlad 1984; Larson and Richards 1991). Many teachers think that their students are disengaged in class and show little awareness of their own learning process. The mostly heard complaint is that students do not prepare for class as they make only little use of instructional materials, extracurricular activities and assignments, and

\footnotetext{
M. Buijs $(\bowtie)$

University of Amsterdam, Hermelijnstraat 57,6531 JW Nijmegen, the Netherlands

e-mail: m.buijs@liemerscollege.nl

W. Admiraal

Leiden University, Wassenaarseweg 62A, 2333 AL Leiden, The Netherlands

e-mail: w.f.admiraal@iclon.leidenuniv.nl
} 
feedback of teachers to learn outside school. This lack of engagement outside school also leads to a passive attitude in class: Students complete the minimum of exercises that is needed for their exam (Battin-Pearson et al. 2000; Jonassen and Blondal 2005; Allen et al. 2007)

However, certain educational designs might promote excitement and engagement. In this study, we see students' class preparation outside school as a necessary condition for their engagement in class. The problem of this study therefore is how students can be encouraged to prepare class, not with the primary objective of gaining knowledge, but with the aim to become more engaged and active during the lesson.

\section{Student learning, engagement, and homework}

Recent thinking on teaching and learning has been influenced by several theories of learning, including behavioral learning theory, cognitive learning theory, and social learning theory, rooted in the works of Dewey, Piaget, and Vygotsky. Jonassen et al. (1999), in their constructivist approach to learning with technology, described instructional principles or characteristics of learning environments which are based on a synthesis of several theories of learning. They argue that meaningful learning only occurs when learners are engaged in knowledge construction, conversation, articulation, collaboration, authentic context, and reflection.

Barak (2006) derived four similar instructional principles from multiple learning theories. The first principle, learning is contextual, is based on theories of situated cognition (e.g., Brown et al. 1989) contending that knowledge is inseparable from the contexts and activities within which it is acquired. Learning occurs only when students process new information in a meaningful way that makes sense within their own frames of reference. The second principle is learning is an active process. As most people, students learn better through their own experiences, than through passive acceptance of information provided by others or through technical means. Students actively construct knowledge by integrating new information and experiences into what they have previously come to understand, revising, and reinterpreting old knowledge in order to reconcile it with the new. Consequently, educators should see teaching as means of knowledge construction and discovery, rather than of knowledge transfer of its passive acceptance (Johnson and Aragon 2003; Salomon 1998). The third principle, learning is a social process, is based on the work of Vygotsky (1978). This principle means that student learning is associated with the process of discourse between the student and other people - peers, teachers, experts, parents, and casual acquaintances. Lave and Wenger (2002) combine the first and third principle as they claim social learning to be a function of the activity, context, and culture in which it occurs (i.e., it is situated). Social interaction is a critical component of situated learning-learners become involved in a community of practice which embodies certain beliefs and behaviors to be acquired. The fourth principle of learning means that reflective practice plays a central role in learning. In his landmark work on reflection, Schön described the concept of reflectionin-action as consisting of "on-the-spot surfacing, criticizing, restructuring and testing of intuitive understanding of experienced phenomena which often takes the form of a reflective conversation with the situation" (Schön 1983, pp. 241-242).

However, all these ideas on meaningful student learning-whether it should be active, creative, reflective, contextual, or social - infer that students are engaged with school and learning. Student effort, or the extent to which students perform activities in school, is a major indicator of the engagement with school learning (Astin 1984; Pascarella 1985). Kuh 
et al. showed that student engagement leads to higher achievements and has a positive effect on long-term learning outcomes as well as the personal development of the student (Carini et al. 2006; Kuh 2009). Stoeber et al. (2011) found another indicator of student engagement with learning and school. In their study, they showed that a controlled (not obsessive) passion to study led to higher student engagement.

Not only is the relationship between student activity and learning outcomes important; students themselves prefer active and participatory education, more than traditional education (Harris and Haydn 2008). Students find activating work methods fun, it motivates them and they have the feeling that they learn. Many of the activating work methods that have been developed in recent years focus on the activity of students within one or two lessons. The extent to which activating work methods in class actually lead to activities of students is often impeded by a lack of class preparation of the students. Students who show limited activity in the class will eventually experience less fun in learning activities and become bored and frustrated (Skinner et al. 2008).

So, one of the ways to stimulate student activity and student motivation is the work they do on homework. Homework can be defined as any task assigned by schoolteachers intended for students to carry out during nonschool hours (cf., Cooper 1989). Generally, a positive relationship is found between doing homework and school results. In their review of research on effects of homework, Cooper et al. (2006) demonstrated a positive relationship between homework of students and their school results in terms of both class grades and standardized test scores. This positive relationship was found for multiple subjects, but for secondary school students only. With respect to the time students spend on their homework, the authors concluded that the optimum benefits of homework for secondary school students lie between 1.5 and $2.5 \mathrm{~h}$. Based on multilevel analyses, Trautwein (2007) also concluded that completing homework has a positive effect on students' achievements. The author only found a positive effect of the frequency of working on homework assignments, not of the average amount of time students spent on their homework. However, Epstein and Van Voorhis (2001) concluded that students performed better in school when they spent more time in general on their homework. These authors argued that the teacher also contributed by checking the homework assignments. Finally, Paschal et al. (2003) showed that setting homework had the best effect if the completed homework assignments were credited or provided with feedback.

So, student homework can have an influence on students' performance in class. Despite the growing knowledge based on the relationships between homework and achievements, four problems came up with drawing conclusions about the value of homework assignments in secondary education (cf., Cooper et al. 2006; Corno 1996). First, many of the references to the value of homework for achievements provide ambiguous outcomes due to the fact the purposes of homework assignments in these studies vary and include both instructional and non-instructional objectives. Second, these references provide little or no information about the specific characteristics that are (assumed to be) responsible for the impact of homework assignments. Third, as Cooper et al. (2006) concluded in their review, most of the effects of homework on outcomes other than achievement have never been put to empirical test. Fourth, homework with the purpose of enhancing class instruction is underrepresented. Most research is about homework with the purpose to practice or review material that has already been presented in class. Mulhenbruck et al. (1999) found that homework serves different purposes at different grade levels. Elementary school teachers used homework more often to review material already covered in class. Secondary school teachers were more likely to use homework to prepare students for work yet to come and to enrich classroom activities. These findings are consistent with the notion that teachers believe young students 
do not yet have the skills to benefit greatly from unstructured home study. Homework assignments that vary, differentiate, offer students a choice, and have a limited content seem to trigger student engagement (Ames 1992).

Therefore, in this study, we focused on the relationship between homework in terms of preparation assignments with the purpose to enhance class instruction. The problem of this study can be formulated as What kind of homework assignments trigger student class participation? Five research questions were distinguished:

1. What are the effects of the various homework assignments on students' time on task and their level of participation in class?

2. Are these effects different for boys and girls?

3. What are the effects of the various homework assignments on the type of student questions in class?

4. What are the effects of the various homework assignments on students' class motivation and their perceived learning outcomes?

5. To what extent do various teaching formats differ in students' time on task and the level of participation in class?

\section{Method}

The research design can be understood as a series of design experiments with a pre-test post one-group only design. The effects of four homework assignments were examined in two groups of 25 students (see Table 1). In each group, two pre-tests were carried out to set a baseline of time on task and the level of student participation. In these two lessons, students were provided with homework assignments in a regular manner: a combination of text reading and textbook assignments. In both groups, four post-tests were administered; one in each instructional strategy, and a delayed post-test was administered for group 1 only. The study was carried out in teaching history.

\section{Intervention}

The four homework assignments were developed in a pilot study. Eight students, five secondary school teachers, and two teacher trainers were interviewed on design principles of effective homework assignments. These interviews revealed four main design principles that were used to setup the four homework assignments of the current study:

- Students benefit from the possibility to choose their assignments. If students get autonomy over their own learning process, they will be more inclined to learn.

Table 1 The research design

\begin{tabular}{|c|c|c|c|c|c|c|c|c|c|c|c|c|}
\hline & L1 & $\mathrm{L} 2$ & L3 & & & & L4 & & L5 & & L6 & L7 \\
\hline G1 & 01 & 02 & $\mathrm{X} 1$ & 03 & $X 2$ & 0 & X3 & 04 & $\mathrm{X} 4$ & 05 & 06 & 07 \\
\hline G2 & 01 & 02 & X1 & 03 & $X 2$ & 0 & X3 & 04 & $\mathrm{X} 4$ & 05 & 06 & - \\
\hline
\end{tabular}

$O 1$ and $O 2$ pre-test (baseline); $O 3, O 4, O 5$, and $O 6$ post-test; $O 7$ delayed post-test; $X 1, X 2, X 3$, and $X 4$ four different homework assignments; $L 1-L 7$ lessons $1-7$ (one lesson per week) 
- Students should be aware of the aim of each homework assignment. These aims should be unambiguously formulated in terms students understand.

- Homework assignments should be straightforward. Teachers need to be able to apply the instructional activity easily and students should be able to complete the assignments in time.

- Homework should be preparatory for the lesson. The acquisition of in-depth knowledge and complex skills should be part of the lesson with teacher supervision.

Prior to the research, the four homework assignments were piloted with a panel of five teachers, including a teacher trainer, to examine if it is doable and similar in difficulty.

\section{Homework assignment 1: preparing analytical skills (lesson 3)}

This homework assignment 1 promoted knowledge acquisition at home in order to prepare them to practice analytical skills in class. The strategy included four phases, two at home and two in class. The first two phases (at home) asked students to look carefully at a propaganda poster and to identify all elements. This means answering questions as; 'what is happening in the poster', 'who are the people in het poster', and 'do you recognize any symbols used'. The last two phases (in class) asked students to examine the goal and the technique of the poster in order to answer explanatory and analytical questions. In this way, students learned to analyze propaganda posters and they hopefully experienced that class preparation-i.e., going through all phases - resulted in a more profound analysis.

\section{Homework assignment 2: the fragmented assessment (spread over six lessons)}

This homework assignment meant that each lesson students completed a part of a test, spread over six lessons. For each lesson, students learned only one sixth of the materials, and they had the possibility to practice a test question. In class, they had the opportunity to ask questions before completing the part of the test about the materials they studied at home.

\section{Homework assignment 3: jigsaw assignment (lesson 4)}

With the jigsaw assignment, students prepared at home different materials on a complex concept. For example, the concept of National Socialism is spread over four questions (What is an ideology, and what are the characteristics of fascism, racial doctrine and Lebensraum). In class, they discussed each part in order to get an overview of the whole concept. Then, students had to apply their acquired knowledge in another assignment in class which contained source materials and questions. Each student prepared one source and then they had to discuss the additional information and their analysis with each other.

\section{Homework assignment 4: student choice (lesson 5)}

This homework assignment meant that students were allowed to choose their own assignment. All assignments were grouped on topic and difficulty. Students started at home and completed the assignments in class. Students could choose for example, to analyze propaganda posters or to analyze a part of film 'The great dictator'. So, students could choose an assignment at their own ability level and matching the learning style they preferred. 
Participants

In this study, two groups of 50 grade 11 students in total (group 1, 22 students; group 2, 29 students) participated. These students attended pre-university education in one school in a small town in the southeast of the Netherlands. The students were 16 or 17 years old and 35 of them were female.

Data and measures

Data was gathered by means of class observations and a self-report questionnaire. Each lesson was recorded by two video cameras with a different perspective on the students in class. With the observational data, four variables were measured: students' time on task in class, their level of student participation, the questions students asked in class and the teaching formats applied in class. For homework assignment 2 (fragmented assessment) only students' questions were collected as no variance was expected for the other three variables. A delayed post-test was administered in lesson 7 for group 1 only. Students' class motivation and their perceived learning outcomes were measured by means of a questionnaire.

\section{Time on task}

The coding units were $3 \times 6$ units of $30 \mathrm{~s}$ of each lesson. This means that there were eighteen 30 -s coding units per lesson. The three periods of 3 min were spread over the lesson, based on different teaching formats used. Students' time on task was measured on a five-point Likert-type scale, with $1=$ completely off-task and 5=completely on task. Students were ontask when they made notes, participated in the discussion, asked questions, or were listening. Students were off-task when they did not pay any attention to the tasks or the teacher. The time on task was registered for each individual student in class. Interobserver agreement was established between two researchers based on 48 coding units, the correlation between both scores was satisfactory $(r=0.74)$.

\section{Level of participation}

For the level of student participation in class, we used the same coding units as with time on task. Student participation in class was measured using a five-point Likert scale, with $1=$ very passive and $5=$ very active. Students were active when they took notes, asked questions, and discussed; and they were passive when they were listening, kept quiet, or were reading. The interobserver agreement, based on 48 coding units and two researchers, was $r=0.72$.

\section{Student questions}

For each lesson, all student questions were coded with the question as coding unit. Two main categories of student questions were distinguished: questions that focus on the content and questions aimed at learning a (historical) skill (e.g., How can I see the propaganda technique 'prestige' from the source?). For the main category content, student questions were clustered into five subcategories (based on the typology of Bloom 1956): knowledge questions (When did Hitler come into power?), comprehension questions (How did Hitler come into power?), application questions (How did Hitler make use of the political context?), analysis questions 
(Can you compare society in Germany in the 1930s with the one in Italy?), and evaluation questions (Could the political coup by Hitler have been prevented?).

\section{Motivation and perceived learning outcomes}

Students' motivation and their perceived learning outcomes with respect to the four homework assignments were measured in both groups by means of a questionnaire in lessons 7 and 11, respectively (i.e. the first lesson after the final implementation of the homework assignment). The questionnaire was piloted with grade 10 students. Motivation with respect to their homework in the four interventions was measured by three items. First, students had to report the extent to which they completed their homework (on a five-point Likert-type scale with $1=$ in total and $5=$ not at all). Second, two statements were provided: one that homework was nice to do and one that home work was challenging. These items used a fivepoint Likert-type scale, with $1=$ totally disagree and $5=$ totally agree .

Perceived learning outcomes were measured by four statements (on a five-point Likerttype scale, with $1=$ totally disagree and $5=$ totally agree), for each of the four interventions (By doing my homework it improved my understanding of the lesson, doing homework was a meaningful activity, I learned a lot of doing my homework, and it would be good to repeat this homework next time).

\section{Teaching format}

Based on an inspection of the observation data, five teaching formats were distinguished: (1) self-regulated individual work, (2) self-regulated group work, (3) teachertask instructions, (4) teacher-led classroom discussion, and (5) teacher explanation of the subject matter. Each time on task/level of participation unit received a teaching format code (W1, W2, W3, W4, or W5)

\section{Data analysis}

As the two groups did not differ significantly in time on task and level of participation, we merged the data from both classes. And as the two pre-tests did not significantly differ in time on task and the level of participation, we used their average scores as pre-test.

Paired $t$ tests were used between the pre-test, on the one hand, and each of the post-tests and the delayed post-test, on the other hand, to answer research question 1 (with time-on task and level of class participation as dependent variables) and research question 4 (with student motivation and perceived learning outcomes as dependent variables). Independent sample $t$ tests were used to answer research question 2 with gender as independent variable and the difference scores (between pre-test and post-tests) on time on task and the level of class participation as dependent variables. As we performed a series of $t$ test in these cases, we adapted the original significance level of $5 \%$ based on the Bonferroni correction method ( $5 \%$ divided by the number of analyses).

Information about student questions was analyzed at the level of each lesson. Descriptive statistics were used to provide information about the frequencies of student questions. Univariate analysis of variance with Scheffé post hoc analyses were used to answer the research question about differences between teaching formats (question 5). Teaching format was the independent variable and time on task and level of class participation were the dependent variables. 


\section{Results}

Time on task and level of class participation

In Tables 2 and 3, the results for time on task and the level of participation are summarized. For the first homework assignment (preparing analytical tasks), the results of the paired $t$ test showed that students were more on-task and participated more, compared with the pretest $(t$ (44) $=-3.64, p=0.001, d=1.1$ and $t(44)=-2.53, p=0.02, d=0.76$, respectively). We found similar results for the jigsaw assignment. Students were more on-task and participated more, compared with the pre-test $(t(41)=-6.83, p<0.001, d=2.06$ and $t(41)=-6.81, p<0.001, d=$ 2.05 , respectively). In the lesson in which students were allowed to make a choice (lesson 5), fewer students were on-task $(t(40)=2.81, p=0.01, d=0.85)$ than in the pre-test. No significant difference was found in the level of class participation.

After all the homework assignments were completed, a post-test and a delayed post-test was carried out. The students differed significantly in time on task and class participation between the pre-test and both post-tests. Students were more time-on task in lessons 6 and 7 $(t(36)=-7.35, p<0.001, d=2.22$ and $t(26)=-7.95, p<0.001, d=2.4)$, compared to the pretest. Similar results with respect to class participation which showed that students participated more in lesson $6(t(36)=-6.01, p<0.001, d=1.81)$ and in lesson $7(t(1.26)=-7.48, p<$ $0.001, d=2.26)$ compared with the pre-test. This describes the effect of the total amount of homework assignments.

Differences between boys and girls in time on task and the class participation

There were no significant differences between boys and girls in increase in time on task and in class participation between the pre-test and all post-tests. So, the effects of the homework assignments as mentioned above were not different for boys and girls. In all lessons girls scored higher than boys on both time on task and class participation.

Student questions

In Table 4, we summarized the results with respect to the student questions. In the pre-test lesson, the average number of students' questions was 23. In lesson 3 (with the preparation of analytical skills), students asked 26 questions and in the six lessons with the fragmented test, a total amount of 70 questions were asked (only in the first 10 min of each lesson). In the other lessons $(4,5,6$, and 7$)$ fewer questions were asked.

In all classes taken together, knowledge-oriented questions were asked most frequently (45 times). Questions in which students analyzed the subject were asked especially in the

Table 2 Means and standard deviations (between brackets) for time on task and level of class participation

\begin{tabular}{|c|c|c|c|c|}
\hline & \multicolumn{2}{|c|}{ Time on task } & \multicolumn{2}{|c|}{ Class participation } \\
\hline & Pre-test & Post-test & Pre-test & Post-test \\
\hline Preparing analytical skills & $3.86(0.54)$ & $4.22(0.65)$ & $2.89(0.69)$ & $3.17(0.74)$ \\
\hline Jigsaw assignment & $3.86(0.54)$ & $4.45(0.54)$ & $2.89(0.69)$ & $3.74(0.62)$ \\
\hline Student choice & $3.86(0.54)$ & $3.40(0.89)$ & $2.89(0.69)$ & $2.82(0.87)$ \\
\hline
\end{tabular}


Table 3 Means and standard deviations (between brackets) for time on task and level of class participation

\begin{tabular}{|c|c|c|c|c|}
\hline & \multicolumn{2}{|c|}{ Time on task } & \multicolumn{2}{|c|}{ Class participation } \\
\hline & Pre-test & Post-test & Pre-test & Post-test \\
\hline Post-test & $3.86(0.54)$ & $4.50(0.55)$ & $2.89(0.69)$ & $3.60(0.75)$ \\
\hline Delayed post-test & $3.86(0.54)$ & $4.61(0.33)$ & $2.89(0.69)$ & $4.05(0.52)$ \\
\hline
\end{tabular}

preparatory assignment (five times) and the fragmented test (10 times), with a total of 22 questions. Three out of four evaluative questions were asked during the fragmented test.

Student motivation and perceived learning outcomes

In Table 5, we present the results for motivation and perceived learning outcomes, clustered per intervention. Most students $(87.8,91.2,80$, and $75.6 \%$ scale 3 or higher) indicated that they did their homework. Although there were no significant differences between the four homework assignments, the student choice showed the lowest mean score $(M=3.61)$ and the jigsaw assignment the highest $(M=4.24)$. Also with respect to the two items that refer to student motivation (items 6 and 7), we did not find only one significant difference between the four interventions: students reported that they experienced the fragmented test more challenging than the jigsaw assignment $(t(39)=2.96, p=0.005)$.

Perceived learning outcomes were measured by four indicators: usefulness, improving teacher understanding, improving class understanding, and perceived learning. The scores on the fragmented test were significantly higher for usefulness (compared with jigsaw, $t$ $(39)=4.99, p<0.001$ and student choice, $t(38)=3.32, p=0.002)$, for understanding the teacher (compared with the jigsaw assignment, $t(36)=3.40, p=0.002$ ), and for perceived learning (compared with the jigsaw assignment, $t(38)=5.07, p<0.001$ ). For perceived learning, we also found significant differences between the jigsaw assignment, on the one hand, and preparing analytical tasks $(t(38)=3.07, p=0.004)$ and student choice $(t(35)=-3.04, p=0.004)$, both with lower scores for the jigsaw assignment. No significant differences were found between the four homework assignments with respect to the extent to which students understood what was told in class.

Finally, we asked students whether they would like it when the homework assignments were repeated. In two cases, we found a significant difference. The jigsaw assignment again

Table 4 Number of questions asked (in pretest, interventions, and both posttests)

\begin{tabular}{lllllll}
\hline & Total & Knowledge & Comprehension & Application & Analysis & Evaluation \\
\hline Pretest & 23 & 9.5 & 6.5 & 2.5 & 3.5 & 1 \\
Preparing analytical skills & 26 & 10 & 6 & 4 & 5 & 1 \\
The fragmented assessment & 70 & 21 & 33 & 3 & 10 & 3 \\
Jigsaw assignment & 12 & 4 & 4 & 2 & 2 & 0 \\
Student choice & 1 & 1 & 0 & 1 & 0 & 0 \\
Post-test & 13 & 3 & 3 & 5 & 2 & 0 \\
Delayed post-test & 17 & 7 & 7 & 0 & 3 & 0 \\
\hline
\end{tabular}

Pretest is an average of the two pre-tests. The delayed post-test was only carried out in one group 
Table 5 Student motivation and perceived learning outcomes

\begin{tabular}{lllll}
\hline & Preparation analytical task & $\begin{array}{l}\text { Fragmented } \\
\text { test }\end{array}$ & $\begin{array}{l}\text { Jigsaw } \\
\text { assignment }\end{array}$ & $\begin{array}{l}\text { Student } \\
\text { choice }\end{array}$ \\
\hline $\begin{array}{l}\text { I have done the homework for this } \\
\text { assignment }\end{array}$ & $3.95(1.24)$ & $4.11(1.11)$ & $4.24(1.07)$ & $3.61(1.67)$ \\
$\begin{array}{l}\text { I found the assignment useful } \\
\text { I could understand the teacher }\end{array}$ & $3.61(1.34)$ & $4.25(1.14)$ & $3.10(1.36)$ & $3.35(1.25)$ \\
$\quad 3.48(0.82)$ & $3.79(1.08)$ & $3.08(1.13)$ & $3.20(1.29)$ \\
$\begin{array}{l}\text { I could participate better in class } \\
\text { I have learned a lot from this }\end{array}$ & $3.46(1.12)$ & $3.58(1.18)$ & $3.33(1.02)$ & $3.35(1.39)$ \\
$\quad$ assignment & $3.68(0.96)$ & $4.00(1.05)$ & $2.90(1.30)$ & $3.53(1.38)$ \\
$\begin{array}{l}\text { I liked the assignment } \\
\text { I found the assignment challenging }\end{array}$ & $2.93(1.10)$ & $2.60(1.37)$ & $2.56(1.32)$ & $3.13(1.42)$ \\
I find the assignment repeatable & $4.14(1.05)$ & $3.23(1.33)$ & $2.54(1.25)$ & $2.80(1.31)$ \\
\hline
\end{tabular}

generally scored lower than preparing analytical tasks $(t(37)=4.71, p<0.001)$ and student choice $(t(36)=-3.52, p=0.001)$.

Teaching formats and time on task and activity

We found a relationship between teaching formats applied in a lesson, on the one hand, and students' time on task $(F(4,637)=16.72, p<0.001)$ and class participation $(F(4,637)=$ 45.43, $p<0.001$ ), on the other hand. Post hoc analyses (Scheffé) showed that teacher's task instructions led to less time on task of students (all differences with $p<0.029$ ) and lower class participation of students (all differences with $p<0.01$ ). Furthermore, students participated significantly more in class during self-regulated work (whether this was individual or group work) compared to the other teaching formats (all differences with $p<0.001$ ).

\section{Discussion}

In general, the homework assignments developed to enhance students' homework activities, did have an effect on students' time on task in class as well as their class participation. Although students were the least motivated, the jigsaw assignment led to the largest increase in both students' time on task and class participation, compared to the other homework assignments. The strategy of preparing analytical tasks also increased students' time on task and their class participation, compared to the baseline as indicated in the pre-test. Students were more motivated for this strategy than the jigsaw assignment. Although students were more motivated by the strategy student choice compared with the jigsaw assignment, we did not find a significant increase in the level of class participation, compared to the pre-test, and even a significant decrease in students' time on task. Subsequently, students reported to be mostly motivated by the fragmented test: they experienced the strategy as meaningful and challenging, and they perceived the largest learning outcomes. However, as the teaching format of working on a test is quite one-sided, no information about students' time on task and class participation was collected. Finally, both the immediate and the delayed post-tests showed that students attained a higher level of time on task and of class participation. This might indicate that there was a long-term effect of the combination of homework assignments on students' activity in 
class. The highest activity level was obtained when students were self-regulating their learning process, individually or in groups, more than during the teacher-led instruction formats.

Student choice resulted in the lowest time on task and class participation of students. Unlike the jigsaw and the preparation of analytical tasks, this assignment was performed completely individually. The other two assignments had a shared goal, in small groups or in class. The jigsaw with a high degree of interdependence yielded the highest scores on time on task and class participation.

Some critical reflections are justified here. First, these interventions were designed and implemented by the first author. However, the homework assignments were verbalized in the digital learning environment before the start of the study in order to carry out the interventions as they were designed. Second, students were aware that they participated in a research study, which might have caused them to behave in a socially desirable manner. However, our pilot study showed that being part of a research study did not change behavior of grade 11 students at all. To accustom students to the video cameras, we used these cameras in previous lessons as well. Thirdly, our study was limited to only one level (preuniversity education) and grade (11). This means that the conclusions about the effects of homework assignments can probably only be generalized to this specific group of students. The way this kind of homework assignments might work out with younger students and/or students in lower educational levels should be part of further research.

\section{Conclusion}

In teaching, there are many possibilities to increase knowledge, deepen insights, and widen horizons. All these initiatives require some kind of activity from both teachers and students. Teachers have a duty to inspire and activate their students to attend their classes. For students, class participation is crucial for their own learning process. Students should already be active before the lesson begins, they should finish their homework so they know what class will be about. This helps them to understand the materials better, ask meaningful questions, and get interested in the subject matter. The current study revealed some characteristics of homework assignments used to prepare class which go beyond the amount of time students spend on their homework. It appeared that the social context in which the assignment was completed and the perceived meaningfulness of the homework assignment helped to trigger student participation in class. Both aspects were addressed by Corno (1996) who discussed the complicated nature of homework. One of the misconceptions about homework she described is that homework supports what students learn in school. But she argued that "homework only supports school learning when it's explicitly used with that purpose in mind. That is, teachers have to give assignments that both reinforce what they are teaching in school and prompt students to reorganize and extend their learning into new and richer areas" (Corno 1996, p. 28).

But reality is different. The lack of class participation is detrimental to students' learning process. Students tend to be passive in class and teachers get frustrated experiencing that students 'never do anything' which in turn results in a lack of motivation to get students involved. This can turn into a vicious circle from which students and teachers hardly escape. Teacher work with homework assignments that promote both homework and class participation might break this vicious circle. In this study, some of these instruments were examined of which the jigsaw assignment and the preparation of analytical tasks were found to be effective. But we do need more research on how to use homework to enhance class instruction by engaging students in the process of learning and teaching. 
Open Access This article is distributed under the terms of the Creative Commons Attribution License which permits any use, distribution, and reproduction in any medium, provided the original author(s) and the source are credited.

\section{References}

Allen, J., Coenen, J. Kaiser, F. \& De Weert, E. (2007). WO-monitor 2004-2005 VSNU-kengetallen, analyse en interpretatie. VSNU Den Haag.

Ames, C. (1992). Classroom; goals, structures, and student motivation. Journal of Educational Psychology, 84 (3), 261-271.

Astin, A. (1984). Student Involvement: a developmental theory for higher education. Journal of College Student Development, 40(5), 518-529.

Barak, M. (2006). Instructional principles for fostering learning with ICT: teachers' perspectives as learners and instructors. Education and Information Technologies, 11, 121-138.

Battin-Pearson, S., Newcomb, M. D., Abbott, R. D., Hill, K. G., Catalano, R. F., \& Hawkins, J. D. (2000). Predictors of early high school dropout: a test of five theories. Journal of Educational Psychology, 92, 568-582.

Bloom, B. S. (1956). Taxonomy of educational objectives: the classification of educational goals. Handbook 1: cognitive domain. New York: McKay.

Brown, J. L., Collins, A., \& Duguid, P. (1989). Situated cognition and the culture of learning. Educational Researcher, 18(1), 32-42.

Carini, R. M., Kuh, G. D., \& Klein, S. P. (2006). Student engagement and student learning: testing the linkages. Research in Higher Education, 47, 1-32.

Cooper, H. (1989). Homework. White Plains: Longman.

Cooper, H., Robinson, J. C., \& Patall, E. A. (2006). Does homework improve academic achievement? A synthesis of research, 1987-2003. Review of Educational Research, 76, 1-62.

Corno, L. (1996). Homework is a complicated thing. Educational Researcher, 25(8), 27-30.

Epstein, J. L., \& Van Voorhis, F. L. (2001). More than minutes: teachers'roles in designing homework. Educational Psychologist, 36, 181-193.

Goodlad, J. I. (1984). A place called school: prospects for the future. New York: McGraw-Hill.

Harris, R., \& Haydn, T. (2008). Children's ideas about school history and why they matter. Teaching History, 132, 10-48.

Johnson, S. D., \& Aragon, S. A. (2003). An instructional strategy framework for online learning environments. In S. A. Aragon (Ed.), Facilitating learning in online environments. New directions for adult and continuing education, 10 (pp. 31-44). San Francisco: Jossey-Bass.

Jonassen J. T., \& Blondal, K. S. (2005). Early school leavers and the dropout issue in Europe. Available at: http://www3.hi.is/ jtj/greinar/Back\%20on\%20track\%20JTJ\%20og\%20Stella\%202005.pdf. Accessed 4 Sept 2008.

Jonassen, D., Peck, K., \& Wilson, B. (1999). Learning with technology: a constructivist approach. Upper Saddle River: Prentice Hall.

Kuh, G. D. (2009). The national survey of student engagement: conceptual and empirical foundations. New Directions for Institutional Research, 141, 5-20.

Larson, R. W., \& Richards, M. H. (1991). Boredom in the middle school years: blaming schools versus blaming students. American Journal of Education, 99, 418-443.

Lave, J., \& Wenger, E. (2002). Legitimate peripheral participation in communities of practice. In R. Harrison, F. Reeve, A. Hanson, \& J. Clarke (Eds.), Supporting life-long learning: perspectives on learning, vol. 1 (pp. 111-126). London: Routledge.

Mulhenbruck, L., Cooper, H., Nye, B., \& Lindsay, J. J. (1999). Homework and achievement: explaining the different strengths of relation at the elementary and secondary school levels. Social Psychology of Education, 3, 295-317.

Pascarella, E. T. (1985). College environmental influences on learning and cognitive development: a critical review and synthesis. In J. C. Smart (Ed.), Higher education: handbook of theory and research, vol.1 (pp. 1-61). New York: Agathon.

Paschal, Weistein, \& Walberg. (2003). The effects of homework on learning; a quantitative synthesis. Journal of Educational Research, 78, 97-104. 
Salomon, G. (1998). Novel constructivist learning environments and nove technologies: some issues to be considered. Research Dialog in Learning and Instruction, 1(1), 3-12.

Schön, D. (1983). The reflective practitioner: how professional think in action. New York: Basic.

Skinner, E., Furrer, C., Marchand, G., \& Kindermann, T. (2008). Engagement and disaffection in the classroom: part of a lager motivational dynamic? Journal of Educational Psychology, 100(4), 765-781.

Stoeber, J., Childs, J. H., Hayward, J. A., \& Feast, A. R. (2011). Passion and motivation for studying: predicting academic engagement and burnout in university students. Educational Psychology, 31 (4), 513-528.

Trautwein, U. (2007). The homework-achievement relation reconsidered: differentiating homework time, homework frequency, and homework effort. Learning and Instruction, 17(3), 372-388.

Vygotsky, L. S. (1978). Mind in society: the development of higher psychological processes. (Michael Cole, Vera John-Steiner, Sylvia Scribner, and Ellen Souberman eds. and trans). Cambridge: Harvard University Press.

Maartje Buijs. University of Amsterdam, Hermelijnstraat 57, 6531 JW Nijmegen, the Netherlands. E-mail: m.buijs@liemerscollege.nl

Current themes of research:

Student engagement in secondary education.

Wilfried Admiraal. ICLON Leiden University Graduate School of Teaching, Wassenaarseweg 62A, $2333 \mathrm{AL}$ Leiden, The Netherlands. E-mail: w.f.admiraal@iclon.leidenuniv.nl

Current themes of research:

Social-psychological aspects of education.

Most relevant publications in the field of Psychology of Education:

Admiraal, W., Huizenga, J., Akkerman, S., \& Dam, G. ten. (2011). The concept of flow in game-based learning. Computers in Human Behavior, 27, 1185-1194.

Akkerman, S., Admiraal, W., Brekelmans, M., \& Oost, H. (2008). Auditing quality of social scientific research. Quality \& Quantity, 42, 257-274.

Admiraal, W., \& Wubbels, T. (2005). Multiple voices, multiple realities, what truth? Student teachers' learning to reflect in different paradigms. Teachers and Teaching, 11, 315-329.

Admiraal, W. F., Korthagen, F. A. J., \& Wubbels, T. (2000). Effects of student teachers' coping behaviour. British Journal of Educational Psychology, 70, 33-52.

Admiraal, W. F., Wubbels, T., \& Korthagen, F. A. J. (1996). Student teacher behaviour in response to daily hassles in the classroom. Social Psychology of Education, 1, 25-46. 